\title{
AC 2008-1548: TEACHING DIFFERENTIAL EQUATIONS IN A DIVERSE CLASSROOM
}

\section{Taskin Padir, Lake Superior State University}

Assistant Professor, School of Engineering and Technology

Kimberly O. Muller, Lake Superior State University

Assistant Professor, School of Mathematics and Computer Science

\section{Collette Coullard, Lake Superior State University}

Professor, School of Mathematics and Computer Science 


\title{
Teaching Differential Equations in a Diverse Classroom
}

\begin{abstract}
A course on ordinary differential equations is included in the core of almost all undergraduate engineering programs. Therefore, it is common practice to tailor such a traditional course towards an audience of engineering students. What becomes interesting, however, is teaching differential equations when only one section of this course is offered each semester and it is populated by students majoring in engineering, mathematics, chemistry, geology or even sociology.

This paper discusses the methodology adopted to teach ordinary differential equations to undergraduate students at Lake Superior State University (LSSU). Since 2005 fall semester, the 3-credit course has been team-taught by two instructors; one from the School of Mathematics and Computer Science and one from the School of Engineering and Technology. The course covers traditional topics such as first-order equations, second-order linear equations with constant coefficients, Laplace transforms, and systems of first-order equations. The emphasis is on the real-life modeling applications of differential equations.

The small size and highly diverse population of the classroom provide opportunities for students to work on modeling applications of differential equations within an interdisciplinary team. The final projects incorporated into the course cover topics ranging from earth sciences to vehicle systems, electrical circuits to robotics. Given the fact that the course material has an emphasis on linear ordinary differential equations, the final projects are utilized to introduce more advanced topics such as model nonlinearities, parameter uncertainties and numerical methods for solving differential equations. The paper will exemplify the student work and discuss the effectiveness of our methodology.
\end{abstract}

\section{Introduction}

Teaching mathematics in a classroom filled with students from various science and engineering majors poses challenges to the instructor. It seems that even though the students appreciate the importance of studying mathematics for their professional careers, they don't show the same levels of interest. Many students view the mathematics courses as part of their degree requirements only and perform with low levels of motivation in the classroom. The instructor's challenge then becomes to build the bridge from the abstract mathematical concepts to practical applications of the theory. The key to success is to find the right balance between the understanding of mathematics and its applications in one's own field of study ${ }^{1}$. A course on ordinary differential equations works quite well to implement this building the bridge philosophy as many real-life applications yield differential equations as mathematical models.

Examples of teaching a mathematics course with an emphasis on applications have been reported in literature numerous times ${ }^{2-7}$. One common approach is to employ the project based learning (PBL) methods ${ }^{2}$. The students are assigned challenging real-life problems which are typically open-ended and unstructured. This approach seems to work well in classrooms populated by the 
students with similar backgrounds and interests. For example, an engineering mathematics course with an emphasis on numerical methods can easily be redesigned to incorporate the PBL approach to improve student learning ${ }^{2,3}$. It should be noted that the homogeneous classroom population makes it possible for the instructor to select problems or projects that also involve a programming component. It is very likely that the students in engineering majors will have exposure to computer programming by the time they are enrolled in an upper level mathematics course.

The process of linking the mathematical theory with applications has also led to the development of brand new teaching techniques as well as textbooks that are accompanied by technological tools and internet resources ${ }^{4,5}$. One such technique introduces team-based labs into a differential equations course in which students are exposed to extensive numerical experimentation ${ }^{4}$. Another approach is to provide the students with easy-to-use technological tools such as Excel worksheets, MATLAB programs and/or interactive web sites and enforce the use of these tools through homework assignments.

In this paper, a methodology adopted for teaching ordinary differential equations at a small fouryear institution is discussed. Each semester only one section of the course is offered. As a result, the class roster is composed of students from various science and engineering majors. In the sequel, a brief analysis of the classroom demographics will be presented. Then, the details of our teaching methodology will be discussed and examples of final projects completed by our students will be illustrated.

\section{Classroom Diversity}

The School of Engineering and Technology at Lake Superior State University (LSSU) offers ABET accredited undergraduate programs in computer, electrical and mechanical engineering. Approximately 150 students are enrolled in these degree programs. As a degree requirement every engineering student also completes 11-14 credit hours in a degree option such as robotics and automation, vehicle dynamics or digital systems.

MATH 310 Differential Equations is required for students majoring in all engineering degrees as well as mathematics and mathematics secondary teaching. It is a prerequisite for many other courses such as vibrations, fluid mechanics, advanced calculus, mathematical modeling, network analysis and electromagnetics.

A total of 99 students have been enrolled in the course since 2005 fall semester. An analysis of the student demographics showed that 26 mechanical engineering, 24 electrical engineering, 18 computer engineering, 11 mathematics secondary education, 8 mathematics, 5 geology, 3 computer science, 3 chemistry and 1 sociology student took the course. Moreover, the average class size was 16. Figure 1 illustrates the distribution of students enrolled in MATH 310 according to their majors.

It is noted that a substantial number of students majoring in programs outside engineering and mathematics such as geology and chemistry also take MATH 310 even though it is not required for their degree. These students are highly motivated as they plan to pursue a graduate program 
in their field of study. Therefore, they influence the classroom dynamics in a positive manner as strong players.

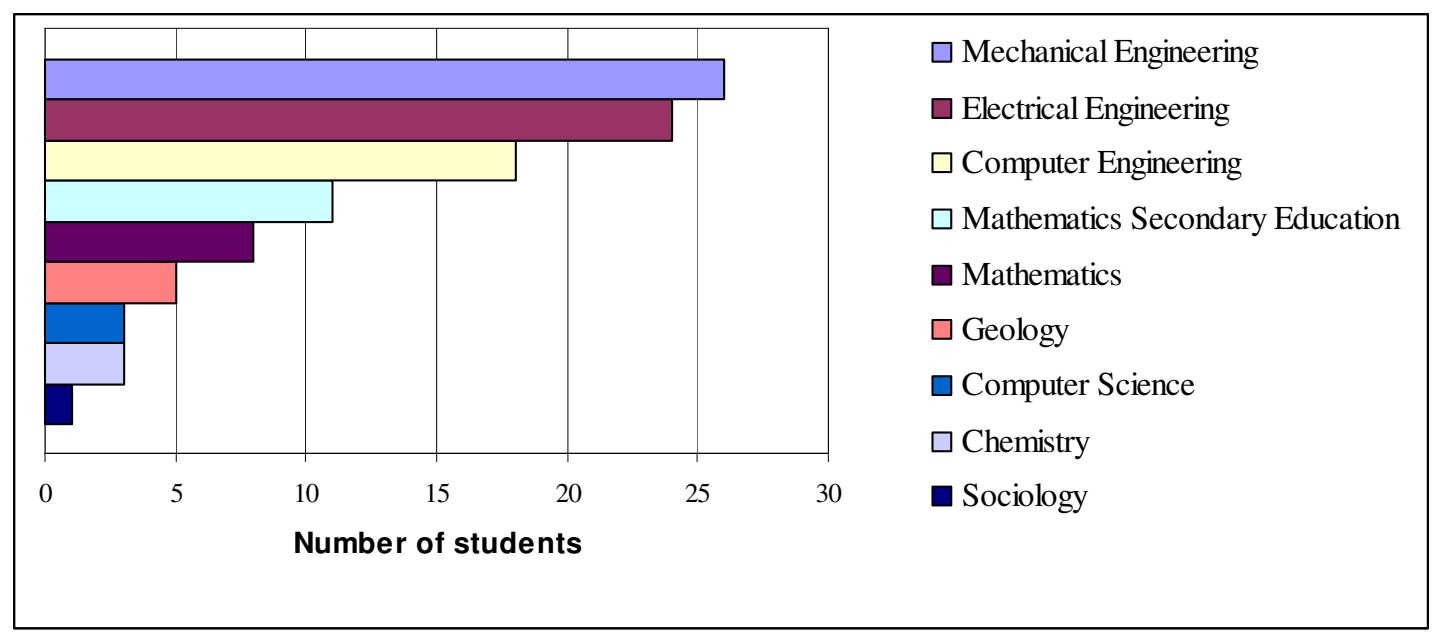

Figure 1 Distribution of students who took MATH310 since fall 2005 according to their majors.

By this quick analysis, it is evident that the instructors of MATH 310 are charged to entertain different backgrounds and interest levels of their students in the course. From this perspective, it may seem that teaching differential equations becomes a challenging task at LSSU. On the other hand, the classroom diversity discussed above provides invaluable opportunities for the instructors to establish a strong link between the mathematical theory of differential equations and real-life modeling applications of engineering, geological sciences, chemical and biological processes. The process of redesigning MATH 310 Differential Equations

taught at LSSU will be discussed next.

\section{Redesigning MATH310 Differential Equations}

In an effort to improve the preparedness of the engineering students on differential equations for their upper level courses, a committee charged by the Schools of Mathematics \& Computer Science and Engineering \& Technology at LSSU remodeled MATH 310 Differential Equations at the beginning of the 2005 fall semester. A set of brand new course objectives was developed based on the feedback from the faculty (see Table 1) and a new textbook was adopted ${ }^{9}$. Moreover, it was decided to teach the course cooperatively by two instructors; one from the School of Mathematics and Computer Science and one from the School of Engineering and Technology. It was rather straight forward to justify this collaboration between the two Schools as engineering students make up approximately $70 \%$ of the class population in MATH 310 every semester.

This collaboration is based on two fundamental principles:

1. The mathematical theory of differential equations is to be presented by the mathematics faculty. 
2. Real-life modeling applications of differential equations such as mixing problems, vibrations of mass-spring systems, and electrical circuits are to be covered by the engineering faculty.

Table 1: MATH310 Differential Equations Course Objectives

\begin{tabular}{|l|l|}
\hline \multicolumn{1}{|c|}{ COURSE OBJECTIVES } \\
\hline Upon completion of this course, students will be able to do the following: \\
\hline 1. & $\begin{array}{l}\text { Differential Equations: Describe the terminology related to differential equations and classify } \\
\text { differential equations (partial/ordinary, linear/nonlinear, etc.) }\end{array}$ \\
\hline 2. & $\begin{array}{l}\text { First-Order Differential Equations: Classify first-order differential equations as linear, separable, } \\
\text { homogeneous, autonomous and exact, solve initial-value problems involving first-order } \\
\text { differential equations, investigate the existence and uniqueness of solutions, obtain mathematical } \\
\text { models and their solutions for applications in mathematics, sciences and engineering using first- } \\
\text { order differential equations. }\end{array}$ \\
\hline 3. & $\begin{array}{l}\text { Second and Higher-Order Linear Differential Equations: Solve homogeneous equations with } \\
\text { constant coefficients, investigate the linear independence of solutions and apply the principle of } \\
\text { superposition, solve nonhomogeneous equations using the method of undetermined coefficients } \\
\text { and variation of parameters, obtain mathematical models and their solutions for applications in } \\
\text { mathematics, sciences and engineering using second-order linear differential equations. }\end{array}$ \\
\hline 4. & $\begin{array}{l}\text { Laplace Transforms: Obtain the Laplace Transform and the inverse Laplace Transform of } \\
\text { functions using the definition or a table of Laplace Transforms, solve initial-value problems using } \\
\text { the Laplace Transform, describe the unit step and unit impulse functions, solve initial-value } \\
\text { problems with discontinuous forcing functions, use the convolution integral in mathematical } \\
\text { modeling. }\end{array}$ \\
\hline 5. & $\begin{array}{l}\text { Systems of First-Order Differential Equations: Obtain mathematical models for applications in } \\
\text { mathematics, sciences and engineering using systems of first-order linear differential equations, } \\
\text { generate the phase portrait for a system of equations, solve homogeneous and nonhomogeneous } \\
\text { systems of equations with constant coefficients using linear algebra methods. }\end{array}$ \\
\hline
\end{tabular}

Feedback from the students who took MATH 310 since 2005 fall semester and the feedback from the faculty of both Schools have been very positive. Students seem to learn more with this new model and are better prepared for their engineering courses such as vibrations, network analysis and design of control systems.

The model for teaching differential equations discussed in this section is based on faculty collaboration; it aims to enhance student learning in a diverse classroom and it is easily applicable in small institutions.

\section{Final Projects in MATH310 Differential Equations}

In this section, we will go back to the original problem posed earlier in the paper and discuss how classroom projects are utilized to link the abstract mathematical concepts to practical applications. Illustrative examples will also be presented.

Differential equations find applications in a large number of real-life problems ${ }^{6-8}$ in engineering, geology or chemistry. The characteristics of the classroom population in MATH 310 described earlier suggest that projects on practical applications of differential equations can be used not only to motivate the students to enhance their understanding of mathematical concepts but also to 
introduce more advanced topics that are omitted in a typical ordinary differential equations course such as model nonlinearities, parameter uncertainties and numerical methods for solving differential equations.

In MATH 310, students are required to select a final project from 3-4 real-life problems presented to them. The projects usually are open-ended and represent the mathematical model for a nonlinear system. Students are encouraged to form multidisciplinary teams even though this is not required. The teams from the 2007 fall semester according to majors and their project topic are presented in Table 2.

Table 2 Student teams in MATH310 according to their majors (2007 fall semester).

\begin{tabular}{|c|c|l|l|}
\hline Team & $\begin{array}{c}\text { Number of } \\
\text { students }\end{array}$ & \multicolumn{1}{|c|}{ Majors } & \multicolumn{1}{|c|}{ Final Project } \\
\hline Team 1 & 4 & $\begin{array}{l}\text { Geology (2), } \\
\text { Mechanical Engineering(1), } \\
\text { Mathematics Secondary Teaching (1) }\end{array}$ & $\begin{array}{l}\text { Vibrations of a 3-story } \\
\text { building in an earthquake }\end{array}$ \\
\hline Team 2 & 4 & Mechanical Engineering (4) & $\begin{array}{l}\text { Vibrations of a 3-story } \\
\text { building in an earthquake }\end{array}$ \\
\hline Team 3 & 4 & Mechanical Engineering (4) & $\begin{array}{l}\text { Motions of a triple } \\
\text { pendulum }\end{array}$ \\
\hline Team 4 & 3 & $\begin{array}{l}\text { Electrical Engineering (2), } \\
\text { Computer Engineering (1) }\end{array}$ & $\begin{array}{l}\text { Motions of a triple } \\
\text { pendulum }\end{array}$ \\
\hline Team 5 & 2 & $\begin{array}{l}\text { Mechanical Engineering (1), } \\
\text { Mathematics (1) }\end{array}$ & $\begin{array}{l}\text { Motions of a triple } \\
\text { pendulum }\end{array}$ \\
\hline Team 6 & 2 & $\begin{array}{l}\text { Computer Engineering (1), } \\
\text { Mechanical Engineering (1) }\end{array}$ & $\begin{array}{l}\text { Vibrations of a 3-story } \\
\text { building in an earthquake }\end{array}$ \\
\hline Team 7 & 2 & $\begin{array}{l}\text { Electrical Engineering (2) } \\
\text { Analysis of Chua's } \\
\text { circuit }\end{array}$ \\
\hline Team 8 & 2 & $\begin{array}{l}\text { Electrical Engineering (1), } \\
\text { Computer Engineering (1) }\end{array}$ & $\begin{array}{l}\text { Analysis of Chua's } \\
\text { circuit }\end{array}$ \\
\hline
\end{tabular}

It is noted that most teams are formed by a blend of students from various disciplines and the topics selected closely match their areas of study. Once the teams are formed, each team is required to meet their instructor to review the problem at hand and decide on a strategy to proceed with the project. In all cases, students must use a software tool such as MATLAB to generate simulation results. Meeting with the instructor regularly outside the classroom and oral reports during the class periods are required to ensure that each team will complete their project on time.

Students are surveyed at the end of the semester as part of a comprehensive assessment process at Lake Superior State University. Students overwhelmingly agree that the final projects help their understanding of modeling real-life problems with differential equations. They also rate the opportunity to work within a multidisciplinary team very highly. Many students comment that the final projects are interesting and enhance their learning. 
Three sample final projects are presented in Appendix A with simulation results obtained by student project teams.

\section{Conclusion}

A methodology for teaching differential equations suitable for small institutions is discussed. The course is team-taught by two instructors, one from mathematics and one from engineering. The instructors utilize the small-class size and the diverse backgrounds and interests of the students to enhance student learning. Students complete final projects on real-life modeling problems with differential equations within a multidisciplinary team. Course assessment surveys and oral feedback from students and the faculty in mathematics and engineering are indicators that our methodology is effective in teaching differential equations to engineering students.

\section{Bibliography}

1. Sazhin, S. S. (1998). Teaching Mathematics to Engineering Students. The International Journal of Engineering Education. 14(2), 145.

2. Bischof, G., Bratschitsch, E., Casey, A., \& Rubesa, D. (2007). Facilitating Engineering Mathematics Education by Multidisciplinary Projects. Proceedings of the 2007 ASEE Annual Conference \& Exposition.

3. Pennell, S., Avitabile, P., \& White, J., (2006). Teaching Differential Equations with an Engineering Focus. Proceedings of the 2006 ASEE Annual Conference \& Exposition.

4. Ruane, M. (2001). Calculus Reform, Differential Equations and Engineering. Proceedings of the 2001 ASEE Annual Conference \& Exposition.

5. Kadijevich, D., Haapasalo, L., \& Hvorecky, J. (2005). Using Technology in Applications and Modelling. Teaching Mathematics and Its Applications. 24(2-3), 114.

6. Enderle, J. D. (2006). Replace Math Taught Differential Equations Course with a BME Taught Modeling Course. Proceedings of the 2006 ASEE Annual Conference \& Exposition.

7. Chaachoua, H., \& Saglam, A. (2006). Modelling by Differential Equations. Teaching Mathematics and Its Applications. 25(1), 15.

8. Affouf, M., \& Zafra, P. (2005). An Individualized Applied Dynamics Project. Mathematics and Computer Education. 39(3), 235.

9. Boyce, W. E., DiPrima, R. C. (2005). Elementary Differential Equations. John Wiley \& Sons, Inc.

10. Matsumoto, T. (1984). A Chaotic Attractor from Chua's Circuit. IEEE Transactions on Circuits \& Systems. 31(12), 1055. 


\section{Appendix A: Examples of Final Projects}

\section{Vibrations of a 3-Story Building in an Earthquake}

Figure 2 illustrates the initial handout given to students on the project. Simulation results are illustrated in Figure 3.

\section{Final Project \#1 Vibrations of a 3-Story Building in an Earthquake}

In this project, you will explore the vibrations of a 3-story building in response to an earthquake. Figure 1 illustrates the building where each floor is represented by a mass of $m$.

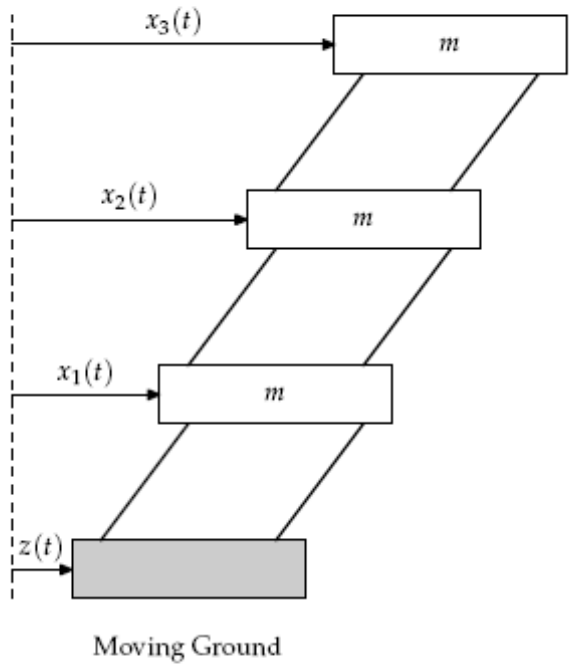

Figure 1: A 3-story building.

The vibrations of the building can be described by the following system of linear equations:

$$
\begin{aligned}
m x_{1}^{\prime \prime}+\gamma x_{1}^{\prime}+2 k x_{1}-k x_{2} & =-m z^{\prime \prime} \\
m x_{2}^{\prime \prime}+\gamma x_{2}^{\prime}-k x_{1}+2 k x_{2}-k x_{3} & =-m z^{\prime \prime} \\
m x_{3}^{\prime \prime}+\gamma x_{3}^{\prime}-k x_{2}+k x_{3} & =-m z^{\prime \prime}
\end{aligned}
$$

where $\gamma$ and $k$ are constants and they represent the building damping and lateral shear forces, respectively. If you choose to work on this project, you will simulate the vibrations of the system under several different circumstances.

Figure 2 Final project handout: Vibrations of a 3-story building in an earthquake. 

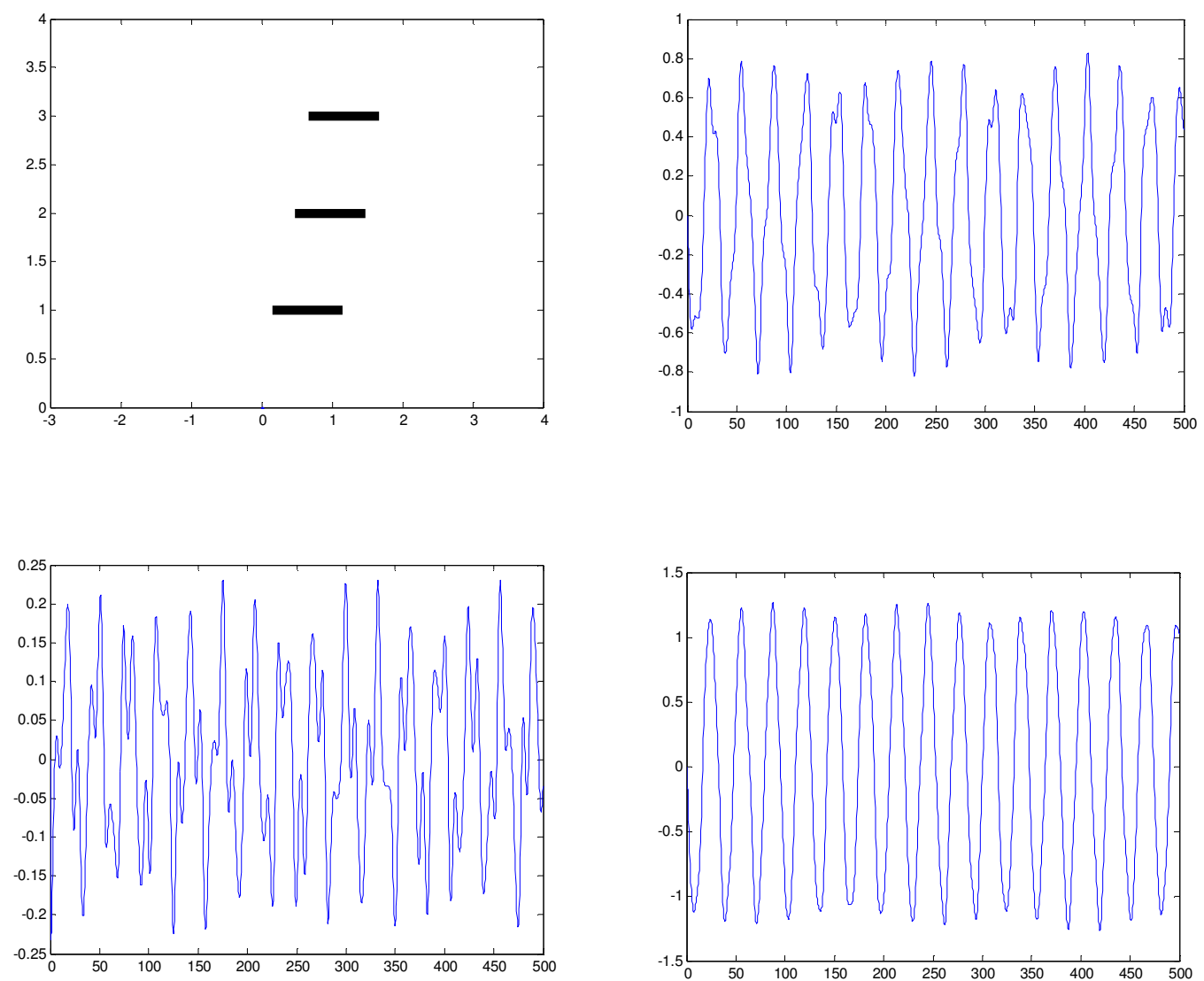

Figure 3 Simulation results illustrating a snap shot of the animated building, and the deviation of each floor from the equilibrium with no damping and an earthquake modeled by a pulse function with duration $0.25 \mathrm{~s}$. 


\section{Triple Pendulum}

Figure 4 illustrates the initial handout given to students on the project. Simulation results are illustrated in Figure 5.

\section{Final Project \#2 \\ Triple Pendulum}

In this project, you will explore the motions of a triple pendulum. Figure 2 illustrates the triple pendulum. Each link has length $l$ and mass $m$.

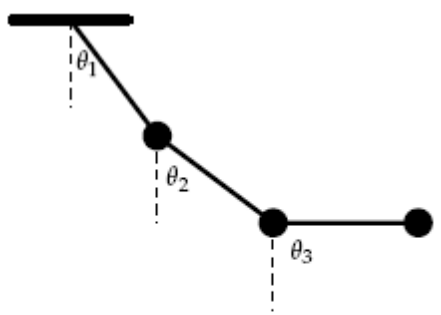

Figure 2: A triple pendulum.

The motions of the pendulum can be described by the following system of nonlinear equations:

$$
\begin{aligned}
\tau_{1}= & 3 m l^{2} \theta_{1}^{\prime \prime}+2 m l^{2} \cos \left(\theta_{1}-\theta_{2}\right) \theta_{2}^{\prime \prime}+m l^{2} \cos \left(\theta_{1}-\theta_{3}\right) \theta_{3}^{\prime \prime} \\
& +2 m l^{2} \sin \left(\theta_{1}-\theta_{2}\right)\left(\theta_{2}^{\prime}\right)^{2}+m l^{2} \sin \left(\theta_{1}-\theta_{3}\right)\left(\theta_{3}^{\prime}\right)^{2}+3 m g l \sin \theta_{1} \\
\tau_{2}= & 2 m l^{2} \cos \left(\theta_{1}-\theta_{2}\right) \theta_{1}^{\prime \prime}+2 m l^{2} \theta_{2}^{\prime \prime}+m l^{2} \cos \left(\theta_{2}-\theta_{3}\right) \theta_{3}^{\prime \prime} \\
& -2 m l^{2} \sin \left(\theta_{1}-\theta_{2}\right)\left(\theta_{1}^{\prime}\right)^{2}+m l^{2} \sin \left(\theta_{2}-\theta_{3}\right)\left(\theta_{3}^{\prime}\right)^{2}+2 m g l \sin \theta_{2} \\
\tau_{3}= & m l^{2} \cos \left(\theta_{1}-\theta_{3}\right) \theta_{1}^{\prime \prime}+m l^{2} \cos \left(\theta_{2}-\theta_{3}\right) \theta_{2}^{\prime \prime}+m l^{2} \theta_{3}^{\prime \prime} \\
& -m l^{2} \sin \left(\theta_{1}-\theta_{3}\right)\left(\theta_{1}^{\prime}\right)^{2}-m l^{2} \sin \left(\theta_{2}-\theta_{3}\right)\left(\theta_{2}^{\prime}\right)^{2}+m g l \sin \theta_{3}
\end{aligned}
$$

where $\tau_{1}, \tau_{2}$, and $\tau_{3}$ are the external forces acting on each link. If you choose to work on this project, you will simulate the motions of the system. Note that this is a nonlinear system.

Figure 4 Final project handout: Triple Pendulum 

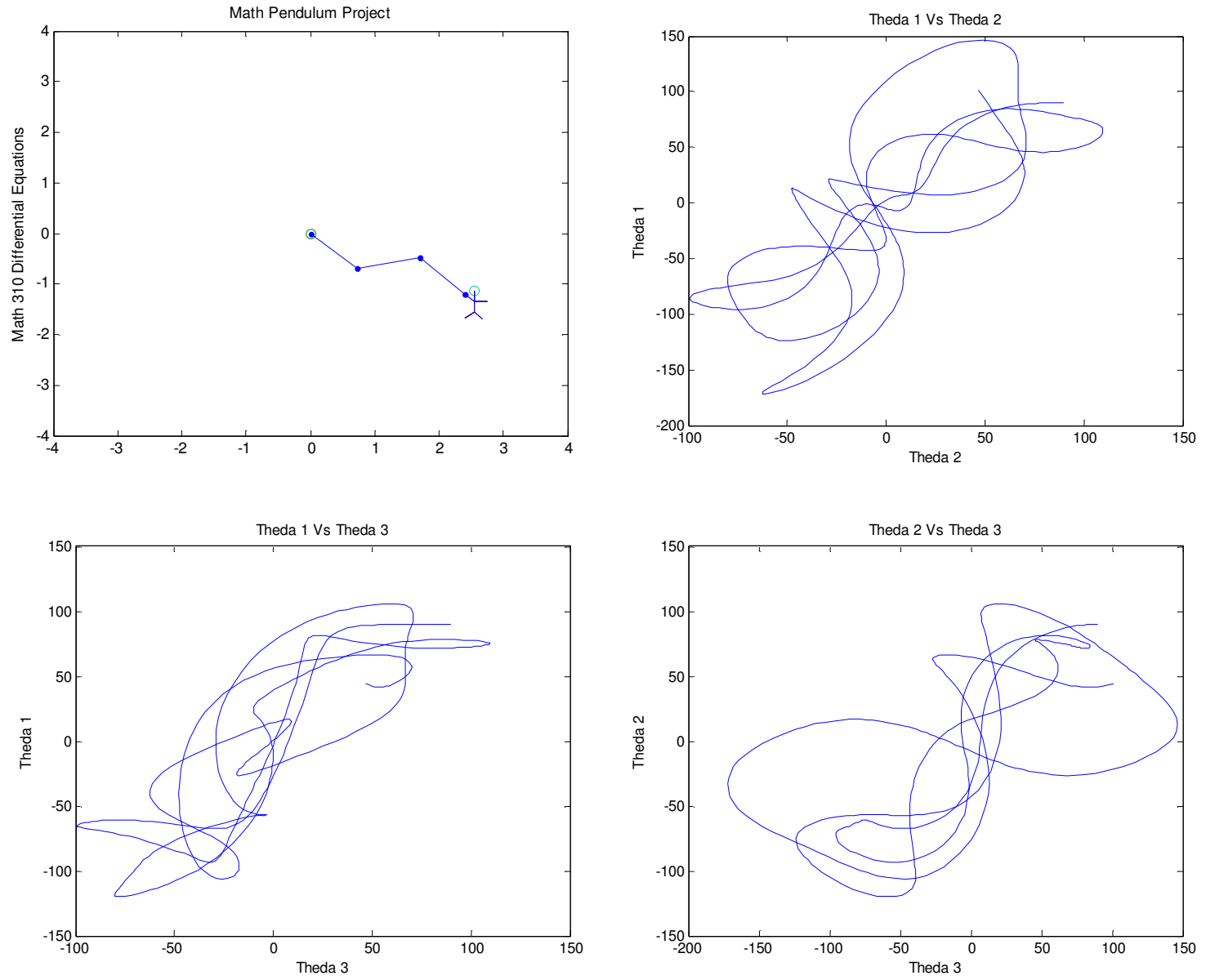

Figure 5 Simulation results illustrating a snap shot of the animated pendulum (while a stick-man is enjoying the ride), and the phase portrait graphs drawn using 2 angles at a time. 


\section{Chua's Circuit}

Figure 6 illustrates the initial handout given to students on the project. Simulation results are illustrated in Figure 7.

\section{Final Project \#3 \\ A Nonlinear Circuit}

In this project, you will explore the behavior of the circuit shown in Figure 3. The circuit contains a nonlinear resistance.

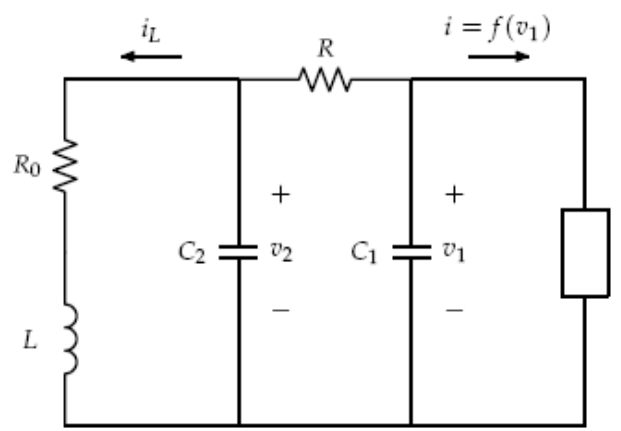

Figure 3: A circuit with a nonlinear resistance.

The system can be described by the following equations:

$$
\begin{aligned}
C_{1} v_{1}^{\prime} & =\frac{1}{R}\left(v_{2}-v_{1}\right)-f\left(v_{1}\right) \\
C_{2} v_{2}^{\prime} & =\frac{1}{R}\left(v_{1}-v_{2}\right)+i_{L} \\
L i_{L}^{\prime} & =-R_{0} i_{L}-v_{2}
\end{aligned}
$$

where $f\left(v_{1}\right)=G_{b} v_{1}+\frac{1}{2}\left(G_{a}-G_{b}\right)\left[\left|v_{1}+1\right|-\left|v_{1}-1\right|\right]$ is the current thorough the nonlinear resistance. This is a third-order nonlinear system and you will simulate its behavior if you choose to work on this project.

Figure 6 Final project handout: Chua's Circuit ${ }^{10}$. 


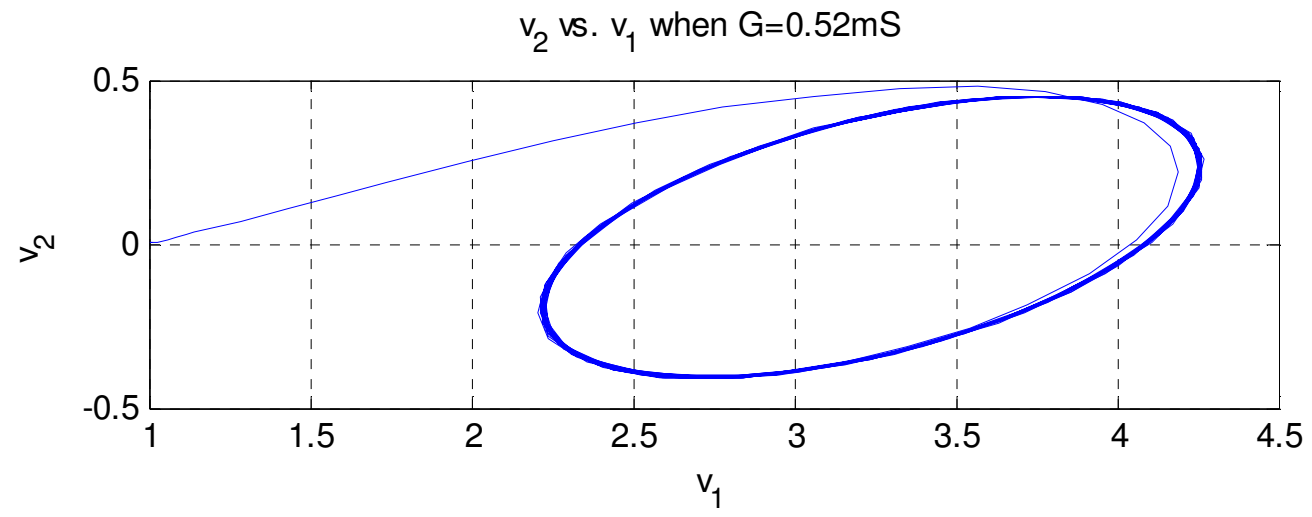

$v_{2}$ vs. $v_{1}$ when $G=0.58 \mathrm{mS}$
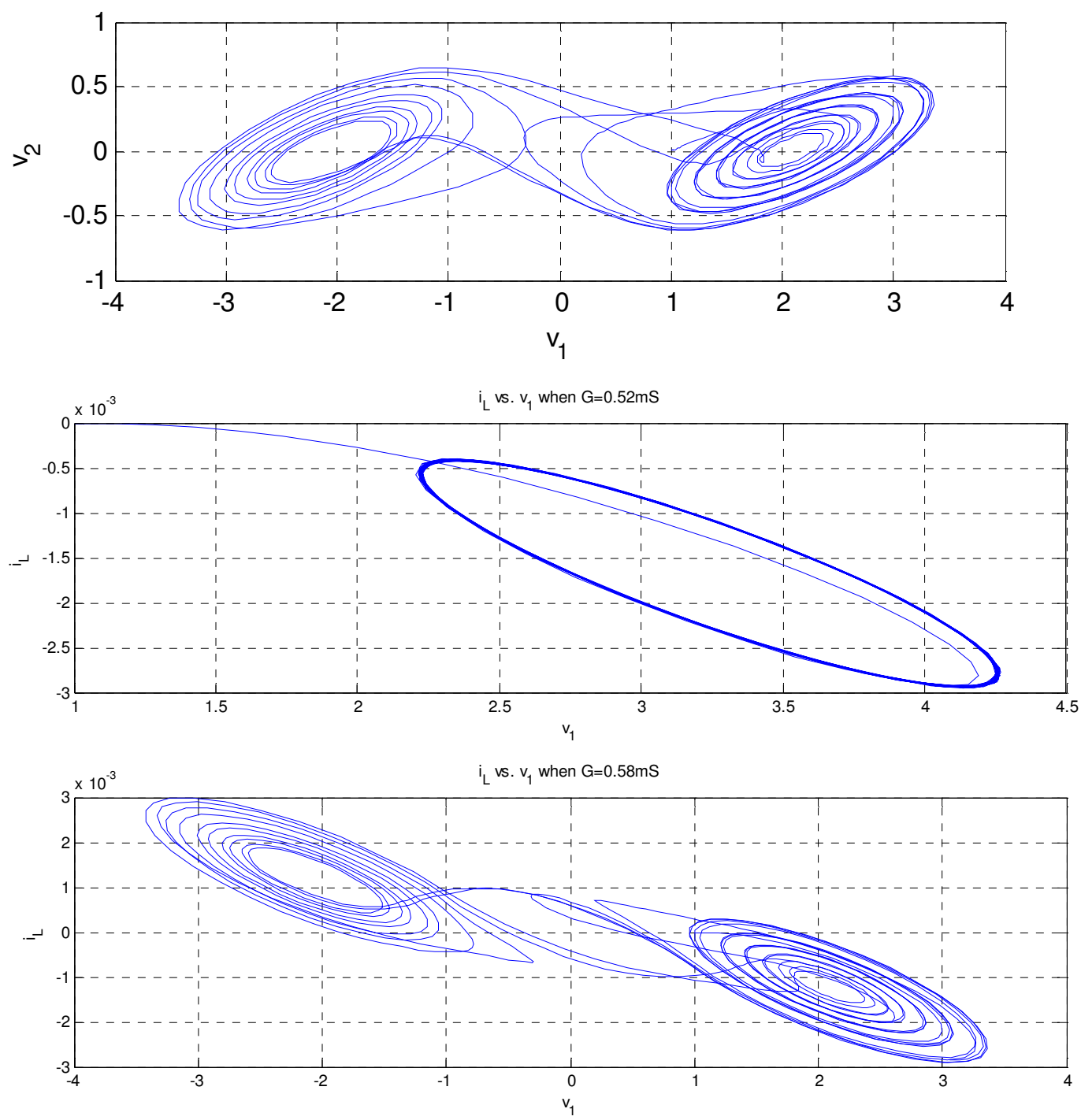

Figure 7 Sample phase portrait graphs for the Chua's circuit illustrating its chaotic behavior.

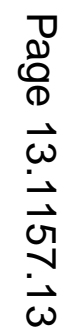

